\title{
E-commerce Analysis in selected European Union Countries: Position of Croatia
}

\author{
Nataša Kurnoga \\ Faculty of Economic and Business, University of Zagreb, Croatia \\ nkurnoga@efzg.hr
}

Ana Slišković

Astellas d.o.o.

ana.sliskovic1@gmail.com

\begin{abstract}
Computer and mobile technology, Internet use and e-commerce have grown enormously in recent years. The main aim of this paper was to analyse the ecommerce of Croatia, the European Union (EU) countries and the post-transition EU countries. Due to technological progress, the paper among other things, analyses the trend of online purchase at the Croatian and the EU level. The analysis revealed the presence of a linear trend. Furthermore, hierarchical and non-hierarchical cluster analyses were used to classify the countries, first at the EU level and then at the level of the post-transition EU countries. Two variables, the Internet use expressed as a percentage of individuals with the last Internet use in the last 12 months and the Internet purchases expressed as a percentage of individuals with the last online purchase in the last 12 months were used to classify those countries. According to Ward's method with squared Euclidean distances and dendrogram, the countries were classified into three clusters, which were then used as the basis for the k-means method. Finally, the cluster analysis resulted in the following three clusters: most developed, developed and less developed. Croatia was classified in the less developed cluster at the level of the EU countries, while at the level of the posttransition EU countries it was classified in the developed cluster.
\end{abstract}

Keywords: cluster analysis, e-commerce, Internet use, multivariate analysis, online purchase, post-transition countries.

JEL classification: C38, L81.

DOI: 10.1515/crebss-2017-0009

Received: November 22, 2017

Accepted: December 22, 2017

\section{Introduction}

E-commerce in Croatia is increasingly evolving due to the increasing use of Internet in business. In Croatia, e-commerce offers a small proportion of products and services that can be an advantage for those who are involved in e-commerce business. Potential obstacles in Croatia are customers who are still turning to traditional forms of trade, and most often due to the lack of confidence in the security of payment and providing personal data for online purchases. Therefore, the 
customers need to be educated what they can expect and how they can protect themselves. In Croatia, great interest has been shown for the development of ecommerce, especially by adopting laws related to e-commerce.

E-commerce has many advantages, but also some disadvantages. Apart from the global marketplace offered by e-commerce, another advantage is manifested in the working hours of 24 hours a day, 7 days a week, 365 days. Furthermore, price comparison is an advantage, as well as available reviews and experiences of other customers, not only about the product or service, but also about the company concerned. Furthermore, there is possibility to search products and services from home and thus saving time.

On the other hand, there are some disadvantages of e-commerce, for example, it is necessary to wait for delivery of the purchased product, then the possibility of false sellers, wrong delivery, or even non-delivery. Besides, for customers who want to try a product, such as clothing or footwear, online purchasing can be an obstacle. Also, entering the necessary data for an e-order requires some time, and there is a possibility for an error while entering the data, then distrust and concern for customer safety as customers want to keep their privacy and protect personal information. Etransactions require personal information, bank account information or credit card number and customers are afraid that the data and funds in the account will be used unauthorized.

Any negative customer experience is harmful for e-commerce and it is therefore necessary to implement market regulation and verification of companies that exist on the Internet.

Knezevic, Jakovic and Strugar (2014) present the research results about the experiences and attitudes of students' population within faculties of economics and business in Croatia about online shopping. Their research revealed that online buyers are positive about the conveniences of online shopping and that non-online buyers are critical towards the difficulties in online shopping.

Saprikis, Chouliara and Vlachopoulou (2010) examined the opinions of Greek university students' towards online shopping. The outcomes revealed the significant differences among the online shoppers and non-online shoppers, where online shoppers had higher expectations regarding the risk and privacy policy.

Furthermore, several Croatian authors have analyzed internet purchases and also internet booking (Dumičić, Čeh Časni, Palić, 2014, Dumičić, Žmuk, Mihajlović, 2016).

Bezić and Gašparin (2009), as the main difficulties of e-commerce implementation in Croatia at that time, mentioned difficulties related to inability of financing, staff inadequacy and the inability of hiring additional workers to maintain an ecommerce system. On the other hand, the most important external obstacles are insufficient transaction security, fear of hackers and viruses, the small potential of ecommerce users, the inadequacy of infrastructure, and lagging in technology. These days we can conclude that there are still many of these difficulties.

The development of information technology created social networks that are also the future of e-commerce. Grbavac and Grbavac (2014) state that social networks are the most popular global communication phenomenon. The reason is that man is a social being and is attracted to and interested in social communication. The authors further point out that the main features of all social networks are universal communication tools and techniques, as well as a shared interest that holds groups of people together. The future of social networks and the development of sales lie precisely in listening to the needs of users and rapidly adjusting retailers to the amount of users. 
Sfenrianto et al. (2017) compared e-commerce and social media in Indonesia. They concluded that usability and online trust are the factors that influence the buying decision in e-commerce and that interactivity and marketing mix are the factors that influence the buying decision in social media. Furthermore, the authors point out that in Indonesia, trading through social media is older than e-commerce, and some products can be found only in social media.

Social networks are newer forms of communication over the Internet, both for individuals and for companies, and are an excellent tool for promoting and selling products. Since there is a possibility of commenting on social networks, all prospective buyers can find out what experiences the buyers had with the purchased product or the company itself. Therefore, it is necessary to be very careful because information is exchanged very quickly on social networks. Furthermore, due to the ability to easily monitor and analyze customer information, companies can interact with customers and respond quickly and efficiently to their needs.

In the context of shopping through social networks, there are many different promotional activities by connecting a larger number of companies. For example, a Croatian brand of women's clothing was associated with a hairdressing and beauty salon and launched a giveaway that functioned in a way that it was necessary to become a companion to all three profiles on a particular social network and to tag certain pictures on all three profiles. At the end, one girl was chosen by random selection and won a free hairstyle, makeup and dress. This activity is a great example of how all three profiles increased their exposure to a larger number of followers, attracted their attention, and got new customers.

\section{Data and methodology}

The paper starts with the hypothesis of e-commerce growth. The next hypothesis is that Croatia is going to classify in the group with the developed post-transition countries. Empirical analysis was conducted in few steps. First, the online purchase for the period from 2007 to 2016 was analyzed for Croatia and then for the EU countries. Furthermore, various cluster analyses were conducted to classify countries in homogenous groups and also to identify in which group of countries Croatia is going to be classified. The analysis was run for $28 \mathrm{EU}$ countries and then for the following eleven post-transition EU countries: Bulgaria, Croatia, Czech Republic, Estonia, Hungary, Latvia, Lithuania, Poland, Romania, Slovakia and Slovenia.

Two chosen variables for e-commerce analysis are as follows: Internet use expressed as a percentage of individuals with last Internet use in the last 12 months (Eurostat, 2017a) and Internet purchases expressed as a percentage of individuals with last online purchase in the last 12 months (Eurostat, 2017b). The last available data for those selected variables were for 2016.

For the classification of the observed countries cluster analysis was used because it classifies similar observations in homogeneous groups, or clusters. Hierarchical and non-hierarchical cluster analyses were conducted, first for the EU countries and then for the post-transition EU countries which are already listed. Various methods of hierarchical cluster analysis were carried out and the Ward's method gave the best solution. After the hierarchical cluster analysis revealed the number of clusters, Kmeans non-hierarchical cluster analysis was performed on selected number of clusters. Finally the results of cluster analyses were compared. 


\section{Trend analysis of e-commerce for Croatia and the EU-28 countries}

Computer and mobile technology have grown tremendously in recent years. The use of the Internet has also grown. Consequently, it is expected an increase in ecommerce. Therefore, the trend analysis of online purchase was carried out at the Croatian and at the EU level.

Figure 1 shows Internet purchases expressed as a percentage of individuals with last online purchase in the last 12 months for Croatia. It can be seen that there is an obvious presence of a linear trend. Therefore, the trend analysis was conducted. The R-squared is 0.9815 and shows that for a given 10-year period the linear trend model explains more than $98 \%$ of the variation in the percentage of people who purchased online. The $p$-value for the regression slope coefficient is 0.000 and this means that time $(t)$ explains a significant portion of the variation in the percentage of people who purchased online.

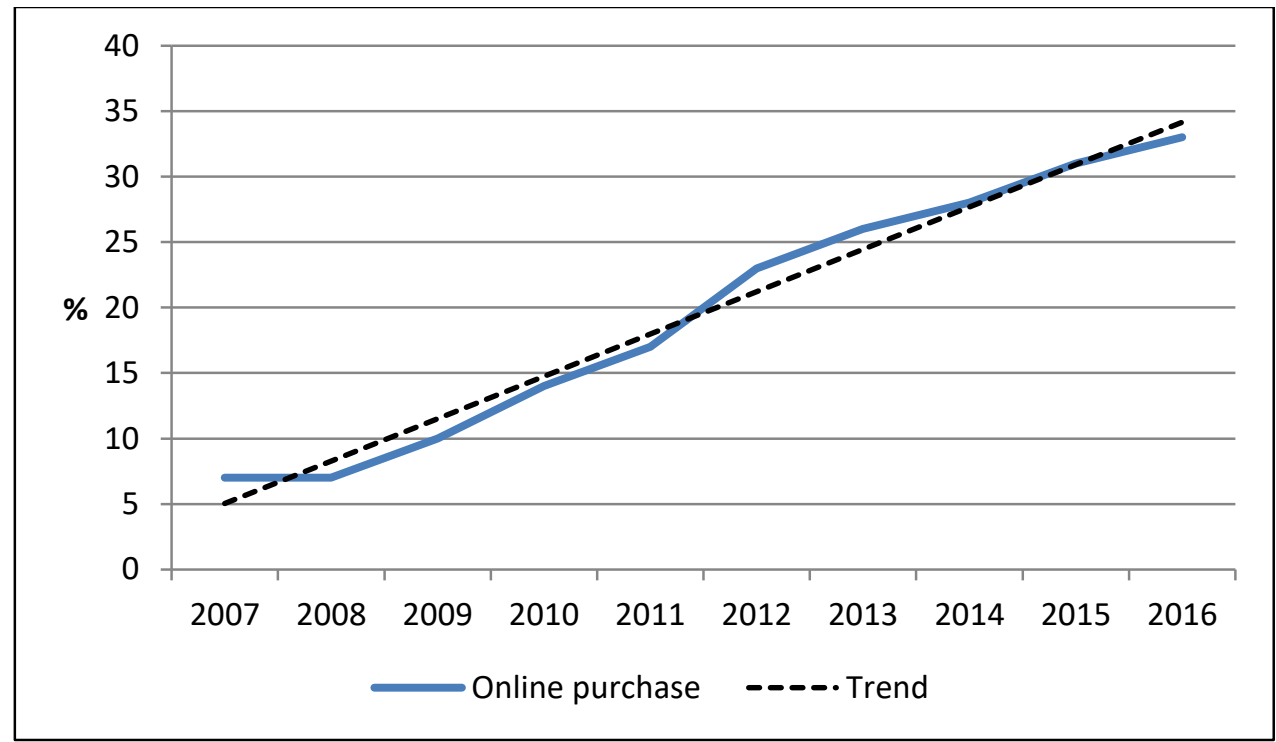

Figure 1 Percentage of individuals with last online purchase in the last 12 months, Croatia

Source: authors' creation, Eurostat, 2017a, b.

Figure 2 shows Internet purchases expressed as a percentage of individuals with last online purchase in the last 12 months for the EU countries. It is apparent the existence of a linear trend and also the trend analysis was conducted. The Rsquared is 0.9944 and shows that for a given 10-year period the linear trend model explains more than $99 \%$ of the variation in the percentage of people who purchased online. The $p$-value for the regression slope coefficient is 0.000 and this means that time (t) explains a significant portion of the variation in the percentage of people who purchased online. 


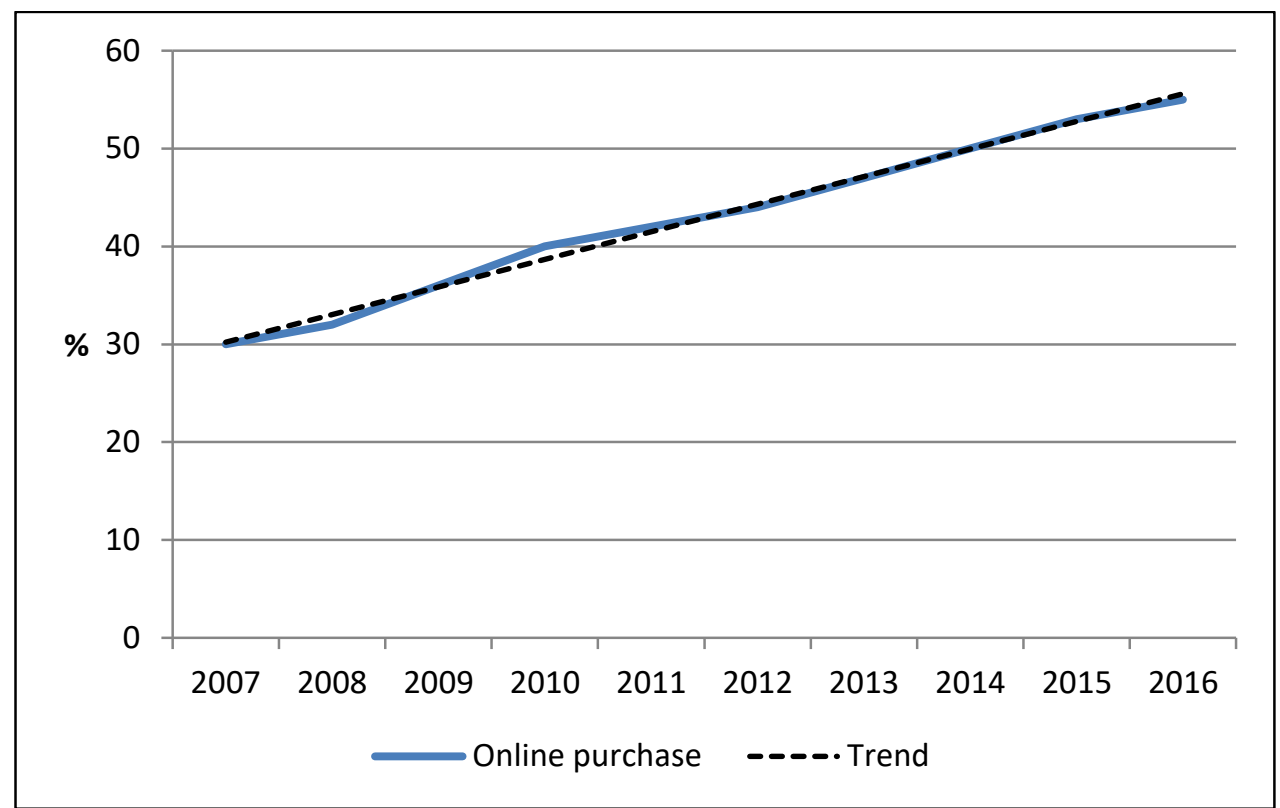

Figure 2 Percentage of individuals with last online purchase in the last 12 months, EU28

Source: authors' creation, Eurostat, 2017a, b.

As mentioned above, there is a significant presence of the linear trend in both analysis, respectively for Croatia and 28 EU countries. Also it can be noted that the Rsquare is slightly larger for the EU countries.

\section{Cluster analysis of the EU-28 countries and the post- transition European Union countries}

Since there is an increase in online purchase, the cluster analysis was conducted to identify the countries with which Croatia will classify in the analysis of EU countries, but also in the analysis of the post-transition EU countries.

Kurnoga Zivadinovic, Dumicic and Ceh Casni (2009) used the cluster analysis to classify European countries according to the selected structural economic indicators where Croatia was grouped with the countries that have similar political and historical background, post-transition countries. Šimurina, Kurnoga and Knežević (2017) classified the post-transition EU countries according the variables on social spending and income inequality, such as unemployment and Internet use where Croatia was grouped with Slovakia due to their high unemployment rates. Furthermore, Bulgaria, Lithuania and Romania were grouped together because they have low Internet use. Authors concluded that the results of cluster analysis support the notion that post-transition countries experience similar problems regarding income inequality.

Hierarchical and non-hierarchical cluster analyses were performed on two variables: Internet use and online purchase. The hierarchical cluster analysis was used to find out the number of clusters and then the non-hierarchical cluster analysis was performed on the selected number of clusters.

First, the cluster analysis was run on 28 EU countries. Several methods of hierarchical cluster analysis were conducted and the Ward's method provided the best solution. Figure 3 gives the dendrogram according to which two to five clusters could be chosen. In the solutions from two to four clusters Croatia was classified constantly with Greece, Portugal, Italy, Lithuania, Cyprus, Bulgaria, and Romania. In 
the five-cluster solution Croatia was stayed with Greece, Portugal, Italy, Lithuania, and Cyprus and Bulgaria, and Romania were separated in the fifth cluster. In all solutions from two to five clusters the following six countries were classified constantly together: Denmark, Germany, Luxembourg, Netherlands, Sweden, and United Kingdom. Finally, the three-cluster solution was chosen because of the linkage distances and intuitive interpretation.

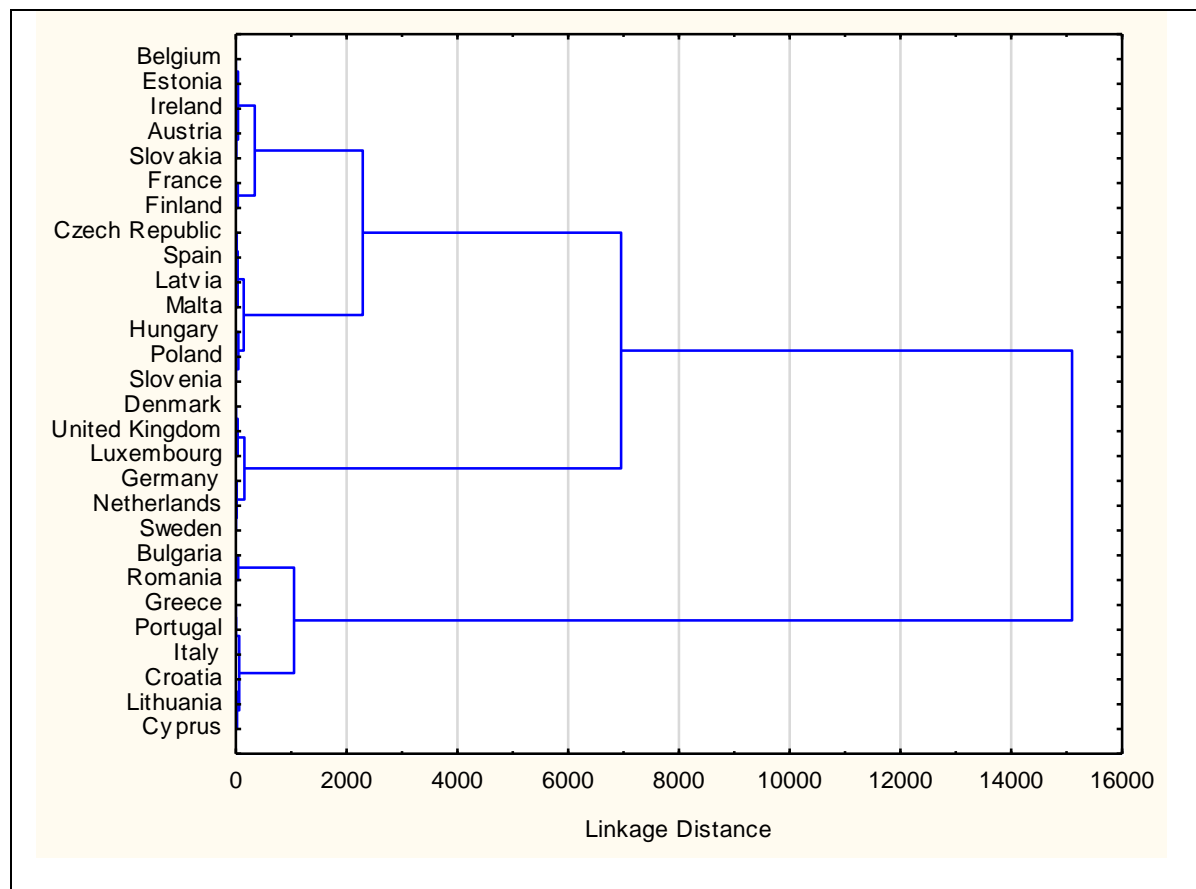

Figure 3 Dendrogram of EU-28 countries, 2016, Ward's method, squared Euclidean distances

Source: authors' creation, Eurostat, 2017a, b.

Table 1 gives the results of clustering for the chosen three-cluster solution according to Ward's method with squared Euclidean distances. The first cluster consists of six most developed countries as it was previously listed. The second cluster consists of fourteen developed countries where seven of them are post-transition countries (Czech Republic, Estonia, Latvia, Hungary, Poland, Slovenia, and Slovakia). The third cluster consists of eight less developed countries, of which four are posttransition countries (Croatia, Lithuania, Bulgaria, and Romania).

Table 1 Clusters, EU-28 countries, 2016, Ward`s method, squared Euclidean distances

\begin{tabular}{|l|l|}
\hline \multicolumn{1}{|c|}{ Clusters } & \multicolumn{1}{|c|}{ Countries } \\
\hline $\begin{array}{l}\text { Cluster 1, most developed } \\
\text { cluster }\end{array}$ & $\begin{array}{l}\text { Denmark, Germany, Luxembourg, Netherlands, Sweden, } \\
\text { United Kingdom }\end{array}$ \\
\hline Cluster 2, developed cluster & $\begin{array}{l}\text { Belgium, Czech Republic, Estonia, Ireland, Spain, France, } \\
\text { Latvia, Hungary, Malta, Austria, Poland, Slovenia, } \\
\text { Slovakia, Finland }\end{array}$ \\
\hline $\begin{array}{l}\text { Cluster 3, less developed } \\
\text { cluster }\end{array}$ & $\begin{array}{l}\text { Bulgaria, Greece, Croatia, Italy, Cyprus, Lithuania, } \\
\text { Portugal, Romania }\end{array}$ \\
\hline
\end{tabular}

Source: authors' creation, Eurostat, 2017a, b.

After the hierarchical cluster analysis, the non-hierarchical cluster analysis was run for the three-cluster solution that was chosen by the Ward's method. K-means 
method was performed and the results are given in Table 2 it can be seen that only difference from the hierarchical cluster analysis is in the clustering of France and Finland. Those two countries were classified to the most developed cluster. The structure of the less developed cluster remained the same.

Table 2 Clusters, EU-28 countries, 2016, k-means method

\begin{tabular}{|l|l|}
\hline \multicolumn{1}{|c|}{ Clusters } & \multicolumn{1}{|c|}{ Countries } \\
\hline $\begin{array}{l}\text { Cluster 1, most developed } \\
\text { cluster }\end{array}$ & $\begin{array}{l}\text { Denmark, Germany, France, Luxembourg, Netherlands, } \\
\text { Finland, Sweden, United Kingdom }\end{array}$ \\
\hline Cluster 2, developed cluster & $\begin{array}{l}\text { Belgium, Czech Republic, Estonia, Ireland, Spain, Latvia, } \\
\text { Hungary, Malta, Austria, Poland, Slovenia, Slovakia, }\end{array}$ \\
\hline $\begin{array}{l}\text { Cluster 3, less developed } \\
\text { cluster }\end{array}$ & $\begin{array}{l}\text { Bulgaria, Greece, Croatia, Italy, Cyprus, Lithuania, } \\
\text { Portugal, Romania }\end{array}$ \\
\hline
\end{tabular}

Source: authors' creation, Eurostat, 2017a. b.

From the plot of means for each cluster shown in Figure 4 it is apparent that the first cluster has the highest values for both variables, which confirms the choice of cluster name, most developed cluster. The third cluster, in which Croatia was classified, has the smallest values for both variables, and this also confirms the choice of the cluster name, less developed cluster. Furthermore, it is evident that the second cluster has values between the values for the first and the third clusters which is also in accordance with the given cluster name, developed cluster.

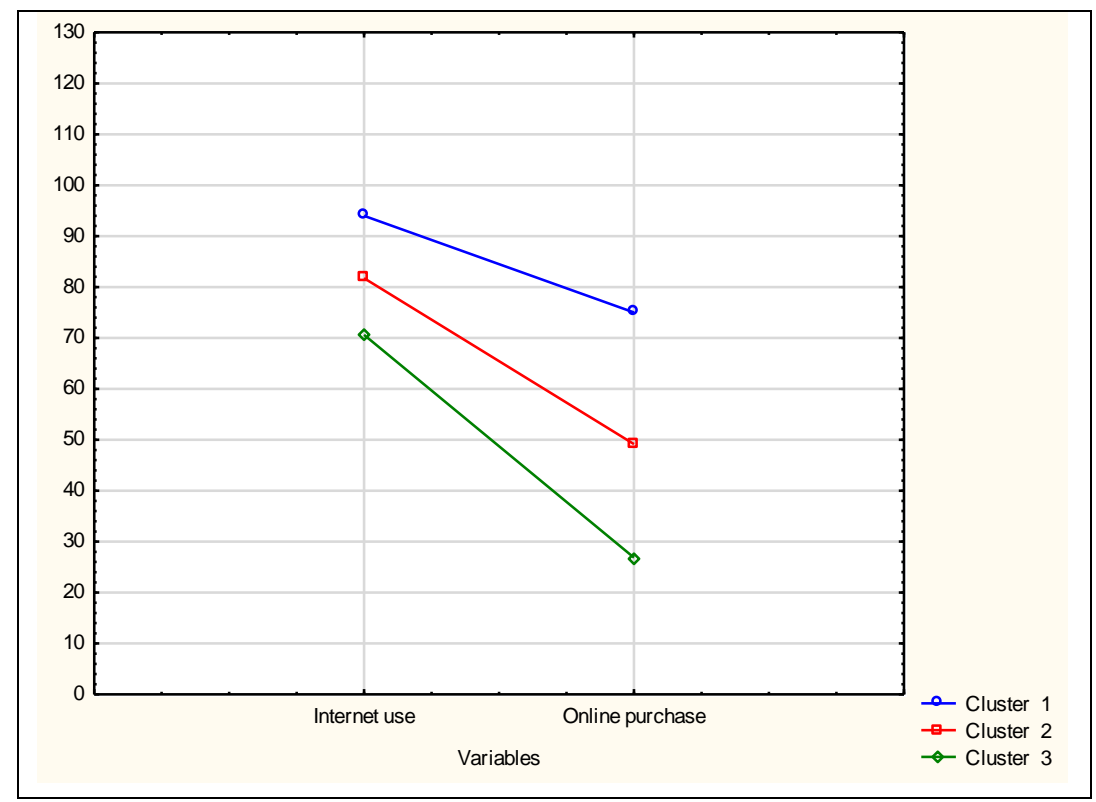

Figure 4 Plot of means for each cluster, EU-28 countries, 2016, k-means method Source: authors' creation, Eurostat, 2017a, b.

Since Croatia is a post-transition country, the following analysis was conducted on the post-transition EU countries. Again the hierarchical and non-hierarchical cluster analyses were performed on two variables: Internet use and online purchase. Figure 5 shows the dendrogram obtained by the hierarchical Ward's method. Based on the dendrogram, the linkage distances and intuitive interpretation the three-cluster solution was selected. 


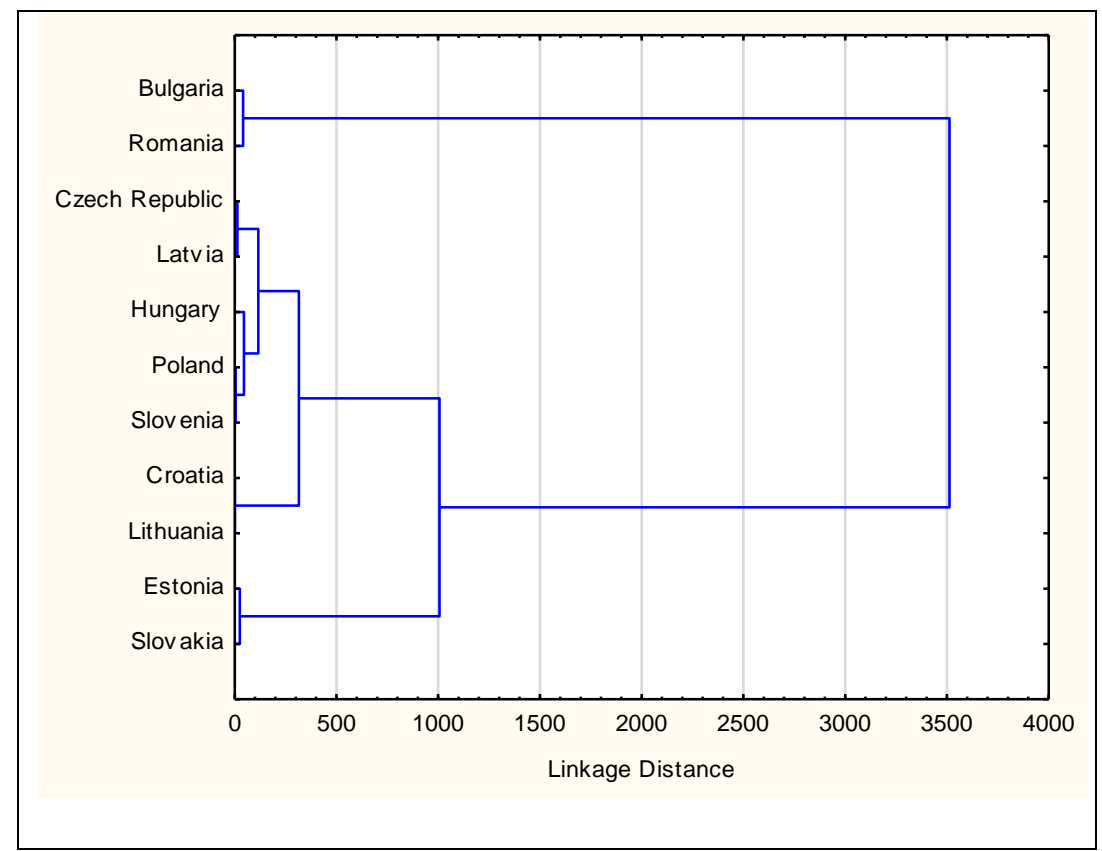

Figure 5 Dendrogram of post-transition EU countries, 2016, Ward`s method, squared Euclidean distances

Source: authors' creation, Eurostat, 2017a, b.

Table 3 shows the structure for those three chosen clusters according to Ward's method with squared Euclidean distances. It can be seen that the clusters are again named: most developed, developed and less developed. First cluster named most developed cluster consist of two countries: Estonia and Slovakia. Those two countries have the highest values for both variables, respectively the Internet use and online purchase.

Table 3 Clusters, post-transition EU countries, 2016, Ward`s method, squared Euclidean distances

\begin{tabular}{|l|l|}
\hline \multicolumn{1}{|c|}{ Clusters } & \multicolumn{1}{|c|}{ Countries } \\
\hline $\begin{array}{l}\text { Cluster 1, most developed } \\
\text { cluster }\end{array}$ & Estonia, Slovakia \\
\hline Cluster 2, developed cluster & $\begin{array}{l}\text { Czech Republic, Croatia, Latvia, Lithuania, } \\
\text { Hungary, Poland, Slovenia }\end{array}$ \\
\hline Cluster 3, less developed cluster & Bulgaria, Romania \\
\hline
\end{tabular}
Source: authors' creation, Eurostat, 2017a, b.

Table 4 Clusters, post-transition EU countries, 2016, k-means method

\begin{tabular}{|l|l|}
\hline \multicolumn{1}{|c|}{ Clusters } & \multicolumn{1}{c|}{ Countries } \\
\hline Cluster 1, developed cluster & Croatia, Latvia, Lithuania, Hungary, Poland, Slovenia \\
\hline Cluster 2, less developed cluster & Bulgaria, Romania \\
\hline $\begin{array}{l}\text { Cluster 3, most developed } \\
\text { cluster }\end{array}$ & Czech Republic, Estonia, Slovakia \\
\hline
\end{tabular}

Source: authors' creation, Eurostat, 2017a, b.

After the hierarchical cluster analysis was carried out, the non-hierarchical cluster analysis was then run on three clusters that were chosen by the Ward's method. Kmeans method was performed on two variables: Internet use and online purchase. The results of clustering are given in Table 4. The only difference from the hierarchical cluster analysis results is in the clustering of Czech Republic which was now classified 
to the most developed cluster. It has already been stated that Estonia and Slovakia have the highest values for both variables, the Internet use and online purchase. Furthermore, Czech Republic has also one of the highest values for the variable Internet use, as well as Estonia and Slovakia and is therefore classified in the most developed cluster.

Figure 6 shows the plot of means for each cluster given by the k-means method. It is evident that the third cluster has the highest values for both variables, which confirms the choice of cluster name, most developed cluster. Furthermore, the second cluster, which consists of Bulgaria and Romania, has the smallest values for both variables and this also confirms the choice of the cluster name, less developed cluster. The first cluster, in which Croatia was classified, has values between the values for the second and the third clusters which is also in accordance with the given cluster name, developed cluster.

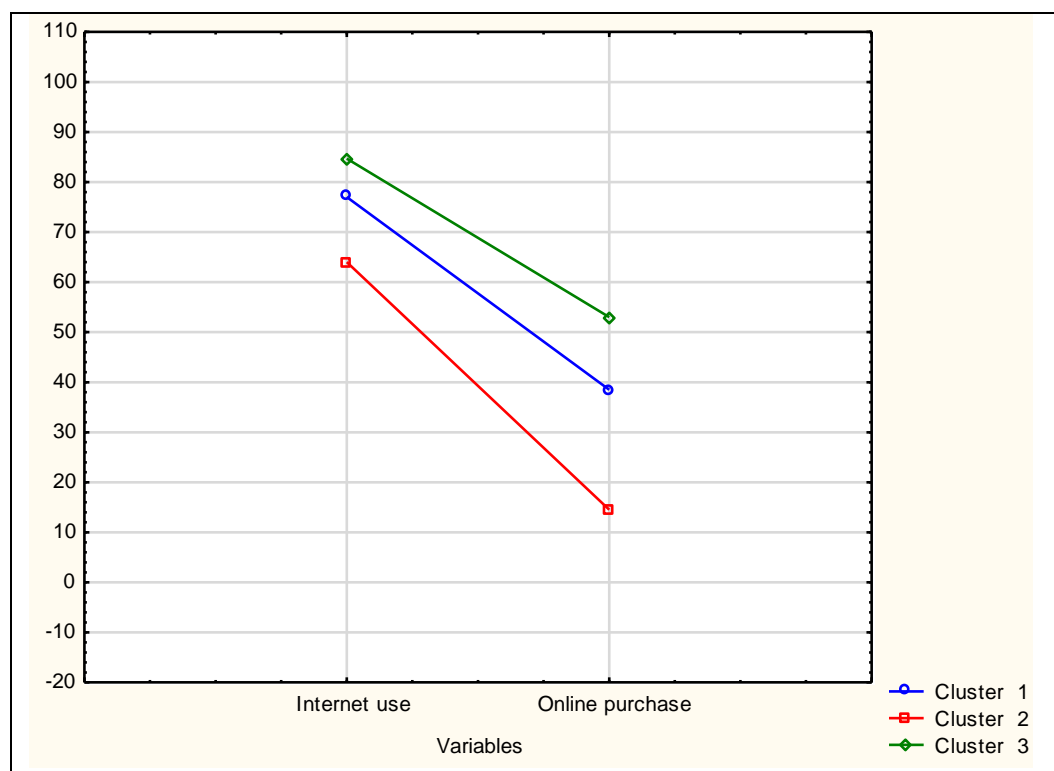

Figure 6 Plot of means for each cluster, post-transition EU countries, 2016, k-means method

Source: authors' creation, Eurostat, 2017a, b.

The results of conducted cluster analyses on two variables, Internet use and online purchase, revealed that Croatia was classified: in the less developed countries in the clustering of the EU countries; in the developed countries in the clustering of the posttransition EU countries.

\section{Conclusions}

Technology, Internet, and e-commerce have developed considerably in recent years. E-commerce offers to buyers more choices, time and money saving, and easy buying, so it is no wonder that it is increasing. There are also some disadvantages of e-commerce, such as waiting for delivery, wrong delivery, non-delivery, or distrust and uncertainty of buyers. Despite these shortcomings, e-commerce finds its way to buyers, both in the EU and in Croatia.

The main aim of this paper was to analyze the e-commerce of Croatia and the EU countries, especially the post-transition EU countries because Croatia is one of them. Trend analysis was first carried out and showed the existence of the linear trend in online purchase, both in Croatia and in the EU. 
Furthermore, another aim was to identify with which countries Croatia is classify according to the Internet use and online purchase, first in the group of $28 \mathrm{EU}$ countries and then in the group of 11 post-transition EU countries. Cluster analysis has classified countries into three clusters in both analysis: most developed, developed and less developed. Croatia was classified in the less developed countries in the clustering of the EU countries and in the developed countries in the clustering of the post-transition EU countries. This cluster solution is in accordance with the values of analyzed variables, respectively Internet use and online purchase.

In this research, only post-transition EU countries were analyzed and in further research all post-transition European countries could be included. Furthermore, a larger number of variables would be included in the next research, concerning the portable devices and mobile connection to the internet. Another limitation of this research is the length of the time series so it should be longer period in further research.

\section{References}

1. Bezić H., Gašparin, A. (2009). Elektronička trgovina U malim i srednjim poduzećima Republike Hrvatske. Ekonomski vjesnik: Review of Contemporary Entrepreneurship, Business, and Economic Issues, Vol. 22, No. 2, pp. 266-281.

2. Dumičić, K., Žmuk, B., Mihajlović, I. (2016). Panel Analysis of Internet Booking of Travel and Holiday Accommodation Indicators. Interdisciplinary Description of Complex Systems, Vol. 14, No. 1, pp. 23-38.

3. Dumičić, K., Čeh Časni, A., Palić, I. (2014). Internet Purchases in European Union Countries: Multiple Linear Regression Approach. International Journal of Social, Human Science and Engineering, Vol. 8, No. 3, pp. 193-199.

4. Grbavac, J., Grbavac, V. (2014). Pojava društvenih mreža kao globalnog komunikacijskog fenomena. Media, Culture and Public Relations, Vol. 5, No. 2, pp. 206219.

5. Eurostat

(2017a).

Internet

use,

Available

at

http://appsso.eurostat.ec.europa.eu/nui/show.do?dataset=isoc_ci_ifp_iu\&lang=en [02 October 2017].

6. Eurostat (2017b). Internet purchases. Available http://appsso.eurostat.ec.europa.eu/nui/show.do?dataset=isoc_ec_ibuy\&lang=en [13 September 2017].

7. Knezevic, B., Jakovic, B., Strugar, I. (2014). Potentials and problems of Internet as a source of purchasing information - experiences and attitudes of university students in Croatia. Business, Management and Education, Vol. 12, No. 1, pp. 138-158.

8. Kurnoga Zivadinovic, N., Dumicic, K., Ceh Casni, A. (2009). Multivariate Analysis of Structural Economic Indicators for Croatia and EU 27. Proceedings of the 2nd WSEAS International Conference on Multivariate Analysis and its Application in Science and Engineering (MAASE'09), pp. 134-139.

9. Saprikis, V., Chouliara, A., Vlachopoulou, M. (2010). Perceptions towards Online Shopping: Analyzing the Greek University Students' Attitude. Communications of the IBIMA, Vol. 2010, pp. 1-13.

10. Sfenrianto, S., Wang, G., Halim, A., Fajar, A. N. (2017). Comparative analysis of ecommerce and social media based trading in Indonesia. IOP Conference Series: Materials Science and Engineering, pp. 1-7.

11. Šimurina, N., Kurnoga, N., Knežević, B. (2017). Cluster Analysis of the Post-Transition Countries of European Union According to the Income Inequality and Social Spending. Proceedings of the 14th International Symposium on Operational Research in Slovenia (SOR'17), pp. 344-349. 


\section{About the authors}

Nataša Kurnoga is an Associate Professor at the Department of Statistics, Faculty of Economics and Business, University of Zagreb, Croatia. She teaches courses: Statistics, Business statistics and Methods of multivariate analysis. Her research interests include statistics for business and economics, especially the multivariate data analysis. She participated in numerous projects and published more than forty papers in scientific journals, conference proceedings and books. She is the reviewer for several international scientific journals. Author can be contacted at nkurnoga@efzg.hr.

Ana Slišković is a Master of Economics (mag. oec.). She finished a graduate study program at the Faculty of Economics and Business Zagreb, University of Zagreb, Croatia. During that time, she gained experience on various student jobs in companies like Hrvatski telekom d.d., Robert Bosch d.o.o., Novartis d.o.o. and others. She is currently working in a pharmaceutical company Astellas d.o.o. Also, she volunteered in a student association estudent and spent one summer in USA, working and learning language. Author can be contacted at ana.sliskovicl@gmail.com. 